\title{
Examining situated design practices: Nurses' transformations towards genuine participation
}

Kija Lin Østergaard and Jesper Simonsen, Roskilde University, Department of People and Technology, Universitetsvej 1, bldg. 8.2, 4000 Roskilde, Denmark

Helena Karasti, INTERACT Research Unit, University of Oulu, FI-90014 Oulu, Finland

$\varnothing$ stergaard, Kija, Jesper Simonsen and Helena Karasti (2018) Examining situated design practices: Nurses' transformations towards genuine participation. Design Studies, vol. $X$, no. $X, p p . X-X$. https://doi.org/10.1016/j.destud.2017.12.002.

\section{Abstract}

We scrutinise the concrete practices of participants' engagement in participatory design through an empirical case in which nurses from different hospital wards began as reluctant users, but gradually engaged in processes approaching genuine participation. We expand a newly proposed, psychologically inspired perspective into a conceptual frame to investigate transformations towards genuine participation. This analytical lens elucidates how participants engage in becoming authentic, credible, attentive and present in participatory endeavours, and how this affects reflection and learning. The case includes the designer's process of becoming a genuine participant during the project. By offering a new take on the concept of genuine participation using a dimension characterised by a genuine, focused presence, we offer our lessons learned from applying the framework.

The concepts, meanings and practices associated with participation vary enormously. In the field of participatory design (PD), the idea of 'genuine participation' continues to attract attention from researchers (e.g. Hägerfors, 1994; Luck, 2007; Robertson \& Simonsen, 2013). Scholars understand that the direct involvement of users in the design of the artefact they will use is desirable (Simonsen 
\& Robertson, 2013), whilst they acknowledge that in everyday situations there are degrees of success in the quality of this participation (Iivari \& Kinnula, 2016). In this paper, we work with a recently introduced novel perspective on genuine participation that draws from psychology and therapy (Simonsen \& Storm Jensen, 2016). We elaborate this perspective into a conceptual framing of genuine participation to examine concrete, situated instances of transformations in nurses' participation that unfolded in our case study of a PD project as part of an information technology (IT) design process.

Early research on participation recognised that there are different degrees of participation, and a variety of typologies has been created for differentiating degrees and kinds of participation (Cornwall, 2008). Arnstein's typology, a 'ladder' of participation (Arnstein, 1969), is perhaps the most well-known and is widely used in many fields, including design, development, education, learning, planning, mental health, and work with youth/children. The ladder identifies significant gradations of shifts in control from the authorities to the participants. In other words, Arnstein's typology ranges from the bottom rungs of 'bad' or absent participation to 'better' ones higher up. Therefore, the more 'genuine' forms of participation can be found at the highest levels of such hierarchical typologies. For example, Luck (2007, p. 219) notes that 'informing, consultation and placation', i.e. the middle rungs of Arnstein's ladder, 'are pseudo-participation approaches and not genuine participation.' The kinds of participation that are referred to as 'genuine' include citizen control, part-taking in mutual learning processes, involvement in decision making, and influence on strategy or policy levels.

Hierarchical typologies make participation seem easily categorised, and the use of the typologies tends to be normative. In actual practices of participation, however, the divisions between the categories blur and participation emerges as less distinct. In fact, as Cornwall notes: 'In practice, all of the forms and meanings of participation identified in the kind of typologies referred to [above] may be found in a single project or process' (Cornwall, 2008, pp. 273-274).

In the participatory IT design tradition to which the authors subscribe, user participation has been an essential part of the situated design practices in the past (Briefs, Ciborra, \& Schneider, 1983; Greenbaum, 1991) and the present (Simonsen \& Robertson, 2013; Smith, Bossen, \& Kanstrup, 2017). In this PD tradition, user participation has been argued by using political, emancipatory and pragmatic rationales (Robertson \& Simonsen, 2013). The political and emancipatory rationales of direct user participation are historically connected to democracy, equal power relations and work- 
life quality (Kensing \& Greenbaum, 2013) to the extent that 'giving a voice to users' ${ }^{6}$ is considered a 'core ethical issue' (Robertson \& Wagner, 2013) and a 'strong normative imperative' often operationalised through addressing user participation in decision making (Bratteteig \& Wagner, 2014). The pragmatic rationale, in turn, emphasises joint development of relevant and necessary knowledge in order to design useful and effective outcomes, which is called 'mutual learning' (Beguin, 2003; Bødker, Kensing, \& Simonsen, 2004).

In this paper, we offer an original take on genuine participation that is substantially different from the existing stances on genuine participation outlined above. This notion of genuine participation that draws on work in psychology and therapy by Storm Jensen $(1998,2002)$ was initially briefly mentioned by Robertson and Simonsen (2013, p. 5) and introduced by Simonsen and Storm Jensen (2016). Aligned with PD tradition, we are interested in 'situated design' (Greenbaum, 1991; Simonsen et al., 2014), or the actual 'doing' in design practice (Bannon \& Ehn, 2013, p. 41), and therefore analyse the dynamics involved in the complex, contextualised 'doing' of participation in practical design situations. We ask: What transformations do the participants experience in their process towards genuine participation in situated design practice?

The case study formed a part of a participatory IT design project in a healthcare setting - a regional hospital in Denmark — where the aim was to redesign the existing paper-based in-hospital follow-up protocol and to support it with a new electronic whiteboard (henceforth, 'e-whiteboard') technology. The case study included a group of user-participants (nurses from different wards) and a designer-participant (also a nurse; henceforward, distinguishing between 'designer' as a general term and 'the nurse-researcher' in this case study). During the design workshops organised by the nurse-researcher, something changed in terms of how the nurses participated, shifting from an initially reluctant participation towards genuine participation - this is the focus of our analysis and discussion.

Our contributions are threefold: Based on the existing initial work by Storm Jensen and Simonsen (Simonsen \& Storm Jensen, 2016; Storm Jensen, 1998, 2002), we develop a conceptual framing for genuine participation that is particularly adapted to participatory design. Second, we use this conceptual framing to analyse the nurses' unfolding and dynamic personal and collective transformations towards genuine participation as part of the situated design practice, and the nurseresearcher's reflections on her 'in-between role' as she also experiences transformations towards 
genuine participation. Third, we present the lessons learned in this study that are applicable to participatory design.

The paper begins by introducing the conceptual framing of genuine participation in section 1 . Section 2 describes the case study, data collection and analysis. Section 3 presents the analysis of the case study, illustrating the nurse-participants' transformations towards genuine participation as well as the nurse-researcher's reflections on becoming a genuine participant. Section 4 discusses the lessons learned and section 5 concludes by describing how these insights contribute to the design research community in general.

\section{A Conceptual Framing of Genuine Participation}

This paper draws on the body-oriented psychotherapeutic research of the Danish psychologist Storm Jensen $(1998,2002)$, whose notion of genuine participation has recently been introduced to participatory IT design (Robertson \& Simonsen, 2013; Simonsen \& Storm Jensen, 2016). Participation is considered to be genuine when the participants do the following:

... participate willingly as a way of working both as themselves (respecting their individual and their group's/community's genuine interest) and with themselves (concentrating on the present in order to sense how they feel about an issue, being open towards reflections on their own opinions), as well as for the task and the project (contributing to the achievement of the shared and agreed-upon goals of the design task and design project at hand). (Robertson \& Simonsen, 2013, p. 5, original italics)

These three characteristics of genuine participation - 'as themselves', 'with themselves' and 'for the task and the project' - addressing basic interpersonal dimensions of the quality of human interaction - are further elaborated below.

Working 'as themselves' refers to being authentic; that is, not pretending, as Simonsen and Storm Jensen explain:

"...not pretending to be anyone else but yourself - or to be anything else but what you are, not pretending to be knowledgeable about something you do not really know, not acting friendly and accommodating if you really are upset and angry and oppose the issue being proposed, not acting as if you are informed and certain if you really have doubts about an issue, etc.” (2016, p. 46) 
We may be disturbed in our attempt to work as ourselves if we are asked to (or sense that we must) perform in any particular way; this can be especially challenging if we experience anxiety or fear that something will happen if we do not behave in a certain way. Furthermore, 'respecting their individual and their group's/community's genuine interest' (Robertson \& Simonsen, 2013, p. 5) signifies that we are able to represent a genuine interest, i.e. 'being open, honest, and truthful with the interests at stake, as related to the issue discussed' (Simonsen \& Storm Jensen, 2016, p. 46). If we participate as ourselves, we are participating and representing the interest of our group/community in a credible state in which we do not have to pretend to be anything — we participate just as we are.

Working as ourselves is complemented by working 'with ourselves', which refers to being attentive and present, as opposed to absent; in other words, having a bodily grounded presence (Simonsen \& Storm Jensen, 2016). Being present in this respect is a prerequisite for sensing how we feel about important issues that are raised. Participating with ourselves means that we support our own ability and openness to sensing, identifying and reflecting on what is truly at stake for ourselves and for the group/community we represent. The ability to be present is challenged when we are distracted. For example, when it is hard to relate the discussion to our own context and situation because it is too abstract or theoretical; when we feel that we are pressured, stressed or otherwise forced to engage in the participation; or when we find ourselves participating with others who act in dominant, manipulative, patronising, aggressive or otherwise unpleasant ways. Working with ourselves can be facilitated through a confident, non-dominated and undisturbed situation that fosters our comfort and ability to be amply present (Storm Jensen, 2002).

The third characteristic — participating 'for the tasks and the project' — represents the focus and objective of the participation. A few questions we might ask are: 'Why are we participating?' '"What is it that we share?' 'What do we want to achieve together?' The notion that we do something 'for the tasks and the project' constitutes the framing conditions and intentionality for joint activities when the participants momentarily occupy the same space and time, thus 'contributing to the achievement of the shared and agreed-upon goals of the design task and design project at hand' (Robertson \& Simonsen, 2013, p. 5). While the notions of working as themselves and with themselves address inherent interpersonal contact dimensions among the participants (rooted in Storm Jensen's [1998, 2002] psychotherapeutic literature), the notion of doing something for the tasks and the project recognises the shared aim and intentionality of being and participating 
together. This notion thus places working as themselves and with themselves within the context of participatory design by paying attention to the specific participatory IT design activities, processes, results and practical/pragmatic measures of user participation (Simonsen \& Storm Jensen, 2016).

\section{Method}

The case study was carried out in a hospital in Region Zealand, Denmark, with the overall aim of exploring how e-whiteboards could support healthcare staff using the intensive care unit's (ICU) follow-up procedure to improve communication and collaboration in the transfer of patients. The ICU follow-up plan focused on the initial 24 hours after the transfer, which is considered a critical period with regard to the risk of regression in illness and possible patient re-admission to the ICU (van Sluisveld et al., 2013). Nurses from four wards were involved: the ICU and pulmonary disease, orthopaedic and surgical wards (the latter three henceforward referred to as 'general wards').

Twenty-four initial workshops were conducted (day, evening and night shifts, $1-1 \frac{1}{2}$ hours duration) in the four wards where the participants (approximately 85 nurses) identified the challenges in the collaboration of ICU follow-up, their specific needs and suggestions for meaningfully re-designing the ICU follow-up (Brandrup \& Østergaard, 2015). The outcomes of each of the initial workshops were used as material to inform the following workshops. Drawing on the results from the initial workshops, the nurse-researcher drafted a design proposal to be evaluated in two subsequent design workshops. The nurse-researcher's proposal featured an ICU follow-up plan in a checklist format, consisting of items to be ticked off when completed and time stamps in accordance with the traditional use of checklists in safety management in healthcare (Hales \& Pronovost, 2006). Two nurses from each ward ( $n=8$, pragmatically chosen) and a clinical nurse specialist (affiliated with the ICU) participated in two design workshops that each lasted three hours.

The two design workshops were audiotaped with a voice recorder and videoed using two cameras to capture two different angles. The audio recordings were transcribed partly by the nurse-researcher and partly by an assistant. Thematic content analysis was initiated. In the ensuing joint analysis sessions with the co-authors, the nurse-researcher described the overall 'storyline' of the workshops, referring to the themes in the transcripts. The challenges that the nurses encountered together with the turns in the storyline made the co-authors of this paper think about the notion of genuine participation as a candidate for conceptual framing for a more detailed analysis of the workshop activities. The notion of genuine participation was then used as an analytic lens to draw 
attention to the communicative interactions and interpersonal dynamics in the unfolding processes, and to identify episodes where shifts in the quality of participation had taken place in the design workshops. The episodes, presented in section 3, illustrated the participants' transformations towards genuine participation and reflected collective and collaborative learning. The quotes in this paper were selected as they exemplify when a participant was going through transformations towards genuine participation. Inspired by the framework of genuine participation, the nurseresearcher started to reflect on her own unfolding participation and consider how the nurses' transformations affected her biases. How did she recognise the importance of and respect the general wards' work? How did she recognise the benefits of being in-between roles during the design process while being comfortable as both a nurse and a researcher?

\section{Nurses' Transformations Towards Genuine Participation in Situated Design Practices}

The analysis of how the nurses changed from reluctant users to participating in a genuine manner in the two design workshops is exemplified in sections 3.1-3.3. The nurse-researcher's reflections on her journey towards genuine participation are presented in section 3.4.

\subsection{Meeting one another 'as themselves'}

This episode demonstrates how the nurses' participation started with frustration and criticism, but progressed to listening and reflection, thereby enabling them to meet one another 'as themselves'.

During the first design workshop, the nurses from the wards spent the first 90 minutes criticising the e-whiteboards and the fact that the hospital used different IT systems between the general wards and the ICU. The nurses interrupted one another and spoke increasingly loudly, while leaning back in their chairs with their arms crossed. It was difficult for them to comprehend why 'the others' could not (or would not) use 'their' IT system, and likewise, it was difficult for them to comprehend the political decision to use different ICT systems within the same organisation. They wondered what was at stake for them, as well as what was at stake for the group, in terms of the ICU followup plan. The nurses agreed that the e-whiteboards and what they represented - bureaucracy, topdown management, being told what to do, and different information systems - did not make sense in their work context. Furthermore, the internal hierarchy within the nursing profession was implicit in discussing these frustrations, with the ICU nurses at the top of the hierarchy (ICU nurses are 
highly specialised and assist the general wards in acute situations). The transfer of patients from the ICU to general wards was addressed as an example; if the ICU needs to transfer an acute patient, the general ward will have to find space for the patient, regardless of overcrowding.

By learning that they shared the same difficulties and frustrations, and that these frustrations were not rooted in a lack of competence but in the fear of not being seen as competent, it soon became clear to the participants that they were not rivals in terms of who was a better nurse. Instead, in the follow-up, they recognised that they were collaborators and that the specific skills of each ward were appreciated, respectively. By sharing their perspectives and reflecting on them, participating as themselves was legitimised; or, more importantly, they became comfortable with engaging as themselves without having to pretend to be better or to know everything. An ICU nurse expressed her respect for the general ward nurses by commenting: "How can you even manage that many patients at once? I mean, wow, and I sometimes feel stressed when I'm in charge of more than one patient at a time". Sharing their frustrations made it possible for the nurses to let down their guard. In addition, they began to reflect on the various problems that they had identified during the initial workshops, including a presentation of preliminary baseline statistics that showed a problematic connection between patient outcomes (in-hospital mortality) and compliance with the ICU followup plan. They realised that the e-whiteboard was the only common system that they could use to exchange data, since the general wards did their documentation using one system and the ICU another, which was only used by the ICU. It was by listening to one another and reflecting on what they had learned that their frustrations, criticisms and feelings of inadequacy towards using the ewhiteboards were eased. The nurses were able to reunite and re-establish a community of nursing that was not 'us versus them', but framed as the interests of one community or group. The frame for the collaboration in the ICU follow-up was established.

The nurses chose to focus on the main issue: patient care. This project could have a major impact on how they typically collaborated during follow-ups, as well as in the transfer of patients in general; the project could be meaningful in their work practices by saving time and supporting their work. Until now, only a few nurses had actively been using the e-whiteboards, and none of them had been using the technology to its fullest potential; however, now they could see the possibilities associated with using the e-whiteboards. During the second half of the first workshop, after learning that they were 'all in the same boat', the nurses decided that they would use the e-whiteboards for this project even though it would be easier for them not to engage with the devices. Doing so would require 
extra work in order to change their habits, but the participants could envisage the benefits; something they had not been able to do when the e-whiteboards were first introduced. They opened a small window for change to happen when they agreed to investigate the use of the e-whiteboards for this project.

The participants began to comment on and guide one another in the direction of the design project, reflecting on how best to approach the new technology. One nurse pointed out to her fellow participants: "Perhaps we could see this [the project] as a good thing - something that might actually help us in our work so that we can concentrate on the core service [the patient]. I mean, instead of just complaining about the things that don't work". Another nurse commented, "Why not just try and make the best of what's been given to us? Let's see if we can make the system work for $u s "$.

During this episode, the nurses went from expressing their frustrations and criticising to listening to one another and reflecting on their own and each other's work conditions. From a guarded position where they were ready to defend themselves and their respective ward against potential (imagined) accusations of not doing an adequate job (not being good enough), they were able to meet one another 'as themselves'.

\subsection{Associating one another 'with themselves'}

The nurses went from defending their own work contexts to reflecting on and mutually and collectively learning from each other's work practices and work conditions, enabling them to participate 'with themselves'.

Based on the results from the initial workshops, the nurse-researcher had created a design proposal in a checklist format - a one-size-fits-all follow-up plan that she introduced in the first design workshop when the participants reached the point of entering the design process to 'see if they could make the system work for them'. Because the participants had established a common ground, they began to challenge the nurse-researcher by questioning why they had to use a one-size-fits-all follow-up plan. They wondered how such a plan could be drafted without including endless options, and how this potentially endless follow-up plan differed from the hand-over summary provided at every patient transfer, which caused even the ICU nurses to become lost in the details. Their opposing view grew from their shared understanding that patients are all individuals. Different 
diagnoses, health trajectories and so forth called into question whether a one-size-fits-all follow-up plan could satisfy each individual's care needs. A related question was whether such a plan would be reasonable - the nurses objected to having yet another task imposed on them, forcing them to compromise their different work practices by having to make the actual work fit into a standardised schema instead of the other way around. This situation led the nurses to discuss relevant issues about former ICU patients - the nurses were open to understanding each other's perspectives and were able to relate to opinions that turned out to be similar to their own. Much of the discussion about work routines and workloads was based on resources in each ward in terms of number of staff (both nurses and physicians), patients and available beds, among other factors. One nurse from a general ward stated the following:

"You [the ICU] may not see it as an issue to hold the mask [for lung therapy] for five minutes, but when I'm responsible for another eight to ten patients who also need care and attention. . . The things I could catch up on within those five minutes [of] just standing there, doing what feels like nothing. It's almost painful'. (General ward nurse, workshop 1)

Once they had gained insight into the other wards' work conditions, the nurses started to reflect on and understand the whys and hows that they had expressed earlier when questioning the approaches of 'the others'. This insight enabled the group to think about how they perceived the ICU follow-up and to reflect collectively on that perception. The participants were surprised to find that they all agreed on almost everything. Each ward could identify with nearly every issue pertaining to ICU patients and the initial 24 hours after their transfer. They even inspired one another and contributed their perspectives to the issues that others had to deal with.

At this point, the nurses realised that the checklist design of the follow-up plan did not accommodate their individual work practices and work conditions. Various problems and challenges in the follow-up were identified during the initial workshops with the four wards. Once nurses from all of the wards were together in the same workshop, they reflected on these findings. Collectively, they discovered that one reason why the follow-up plan did not work was because the foundation for the follow-up plan had not been made in collaboration across wards and thus did not acknowledge the different work practices and work conditions. The traditional checklist format (using time stamps) was too rigid, and sometimes served as a barrier to effective patient care. Because the ICU nurses, who should fill out the follow-up plans, had no insight into the general wards' work routines, they adjusted the time stamps to match their own routines, which did not 
align with those of the general wards. The general ward nurses were concerned that if they adjusted the tasks to suit their work routines, then the time stamps would show a delay in task completion, which could be interpreted as non-compliance with a mandatory clinical guideline. The nurses from the general wards also felt that their professional integrity was being belittled since the follow-up plan's checklist format did not account for professional knowledge, initiatives or flexibility.

In this episode, the nurses began to reflect on and learn from one another's work practices and work conditions. Through this, they were able to associate 'with themselves' by becoming more attentive to their own and their colleagues' situations, and by sensing and reflecting upon what was at stake for their respective wards. Genuine participation stresses the interpersonal reflections within the group; even though the nurses shared the same professional education and background, they also represented different wards and sub-specialities, and therefore different professional and practicebased communities within the primary organisation of the hospital.

\subsection{Taking ownership 'for the project'}

This episode describes how the nurses went from participating because they were told to do so, to proactively participating in the design project.

It was evident to the nurse-researcher that the participants had only attended the workshops because management had told them to. One nurse even explicitly expressed this while the group was being welcomed during the first design workshop: “Well, thank you for welcoming us, but we were told to be here... [laughing]. Our colleagues did not appreciate us leaving the ward'. After presenting the agenda for the workshops - collaboration between the wards and a chance to influence the design to fit their needs - the participants began to pay attention, ask questions, engage and join in the decision making. The participants rejected the nurse-researcher's design proposal (the one-size-fitsall follow-up plan) half an hour into the second design workshop because the proposal did not suit their different work contexts. The nurses from the general wards also perceived that their professional integrity was being diminished by the proposal's checklist format; for example, one sarcastically exclaimed, "Oh, that's great! Now we don't even have to think!"

The participants engaged in a revised design of the follow-up plan and tailored it to their own needs. Leaving behind the suggested design proposal of a 'checklist' and designing an alternative 'attention list' was accompanied by expressions of excitement over the realisation and 
implementation of this revised plan. The entire experience of being invited to join in the design process, the decision making related to the design and a future implementation of the design was new to the nurses. One nurse stated, "This we can actually use ... this could actually help us. Why weren't we asked sooner... to participate in such nurse-related issues?" They recognised the importance of their participation - the project could not and would not succeed without their presence, engagement and participation. More importantly, they perceived the benefits of the project and how the design would be customised to meet their needs instead of being something a designer or a technician (who might not have a clinical background) had created; this was their product, their design. The attention list they developed supported the work of the nurses on the general wards and respected their professional integrity. As it was the nurses' responsibility to manage the tasks/items on the attention list, they would have to plan the different tasks in their work routines, which meant that the plan did not give them the impression of being control-based (as opposed to the former proposal with its checklists and time stamps).

The final design workshop ended with the participants stating that they wanted a third workshop in which they could pilot their design of a follow-up plan, giving them an edge over their colleagues in their respective wards. Having this follow-up plan in place would enhance their feeling of competence after the implementation while also allowing them to pass their knowledge along to their colleagues.

\subsection{The nurse-researcher's reflections}

This section is written in the first person, as the nurse-researcher is also the first author of this paper.

\subsubsection{Meeting one another 'as themselves'}

Because I had worked as an ICU nurse for 12 years at the current ICU, I was confident that I knew what the ICU nurses (my former colleagues) would want. I was considered a 'nurse expert' within the internal hierarchy of the nurses and therefore entered the workshops as 'a nurse expert' with a PD project. The traditional manner of managing projects within health sciences is for the project manager to be in control of orchestrating the processes. As an insider within the group of nurses, I knew the jargon at the hospital; this insider knowledge enabled the participants to speak freely and 
professionally without having to rephrase things in layman's terms or to restrict themselves from expressing the sometimes morbid humour often used in hospitals.

As the participants went through the first episode towards genuine participation, I intervened minimally for several reasons. Mainly, I did not know how to convince them that designing an ewhiteboard support for the ICU follow-up would help them in their daily work, although they could see the point of an effective follow-up from a professional perspective (i.e. the aforementioned preliminary baseline statistics, results from international and national research on ICU follow-up and the results from the previous workshops). It was clear to me that I was proposing something that they resisted: using the e-whiteboards and the change itself. Many of the wards opposed using the e-whiteboards because the nurses felt that they had not been properly introduced to the technology. The participants slowly realised that I did not represent hospital management but was instead a person - a fellow nurse - who was working on a project that I sincerely believed in. Moreover, I shared their frustrations in regards to implementation strategies, top-down decisionmaking and the lack of sense-making in projects within clinical nursing practice. Then they ceased to consider me as a part of 'the other', or 'the enemy', and just as 'me'.

While learning of the hospital wards' diverse work conditions and resources, I became humbled by the general ward nurses. It was through this humbling process - by not pretending to be an expert, not opposing their reluctance and not defending my own design proposal - that the nurses began to respect me. They then viewed the project as one that they could associate with being in their own community's best interest; it also changed their view of me - since I did not try to force something on them, they felt free to discuss their opinions openly.

\subsubsection{Associating one another 'with themselves'}

By associating with the participants, I could see how I had questioned the general ward nurses' intentions in the follow-up. I thought that I knew their jobs better than they did (which was one of the reasons I exclusively came up with the initial design proposal), and having strong roots in and being a part of the hospital setting projected this bias. Understanding their concerns from their point of view enabled me to critically reflect on my own perspectives. I still had my reservations regarding the transfer of ICU patients, but I could also see that the way in which the ICU had imposed its own approaches on the general wards did not align with the wards' work contexts. Learning about the general wards' work conditions was an eye-opening experience for all participants. It emphasised the need for the project to support the general wards when they received 
patients from the ICU, as these patients are usually the healthiest patients when they leave the ICU but become the most ill and critical patients in the general wards upon entering them.

During the second episode of transformation towards genuine participation, I learned that it seemed possible for the nurses to collaborate and even respect one another's work regardless of their affiliated wards. Learning from one another within the group provided insight, respect and understanding of their different work contexts. This all led to participation with ourselves; being inbetween the roles of a fellow nurse and an outsider researcher made it possible for both parties to engage in this process. The nurses could meet me with their criticism because I was part of the nursing community. On the other hand, they needed to test how strong my attachment was to management and the technology leading to change. This particular reflection is one example of how being in-between roles was beneficial in this case of relating to the hospital, the kinds of taken-forgranted assumptions came from this relation and how I had to question these during the process because of what I had learned through participatory design and the processes of genuine participation. The follow-up plan became a collaborative design in which the nurses were designing in a genuine participatory manner, participating with ourselves.

\subsubsection{Taking ownership 'for the project'}

The third episode towards genuine participation also reflected my own limitations, since I had originally thought that I knew what the nurses wanted as a nurse expert myself. By the end of the second design workshop, the participants wanted to have another workshop so they could test their design before it was implemented in their wards. At first, I thought, 'Hey, this is my call — I'm the one who'll decide if another workshop is needed!' The third episode made me feel insecure in my role in the project, even though this outcome - the nurses taking ownership — was what I intended from the beginning. Letting go of my design proposal, leaving behind the role of a project manager and forgetting my agenda allowed me to be more open and reflective in the process. This gave the nurses greater scope to genuinely participate and take ownership of the project. Through engaging in listening to one another, reflection, associating with the group and learning collaboratively, thereby taking ownership of the project, I genuinely became able to focus on the actual reason for being together in the design workshops. 


\section{Nurses' Transformations Towards Genuine Participation: Lessons for Design}

The analysis presents situated accounts of action, reflection and conditions for collaborative learning that emerged in the nurses' transformations towards genuine participation. This is reflected through insights into situated design practice and through the reflections of a nurse-researcher who is a part of the community of practice and an outsider as a researcher. Below, we discuss the situated, practical realities for genuine participation in local activities and the conditions enabling the participants to engage in the design process through collaborative learning.

Researchers' reflexive engagement is discussed by Pihkala and Karasti (2016) as a way to attend to 'participation in plural' in a design project. We recognise that regardless of the participants' assigned roles (as users, designers or researchers), everyone needs to engage in a reflective process addressing their own roles, responsibilities and the decisions they make.

Participatory approaches and exemplars of the reluctant participant in a healthcare setting is a key concern in a PD project carried out by Noergaard et al. (2017), and the designers' roles in PD projects are discussed in several papers (e.g. Crilly, 2015; McDonnell, 2016). Researchers are mostly either outsiders in relation to the work context they are designing for, or are positioned higher in the organisation than the practitioners/users.

Genuine participation challenges the hospital's practices in managing projects. Furthermore, genuine participation challenged the pre-defined design project; it was not until the participants engaged in a more genuine manner that they realised that the design proposal was a reproduction of the traditional system of checklists, restraining the nurses in the organisational structure. This challenged the nurse-researcher's decision to stay true to the original design agenda or empower the participants through their ownership of the design. Ultimately, she chose the latter, leading to a design solution that two expert groups (ICU nurses and general ward nurses) acknowledged as meaningful to their respective nursing practices.

\subsection{Participating as themselves}

The nurses met one another at the first workshop and were anxious about what should or could happen. They were prepared to defend themselves and the interests of the group and ward they represented. This included holding prejudicial views of one another - the ICU nurses perceived the 
general ward nurses as knowing little, while the general ward nurses believed that the ICU nurses thought they had to know everything. Moreover, the nurse-researcher believed that her way was the best way.

The initial 90 minutes of heated discussion on their critical experiences created a space in which the nurses could also express their fears: the fear of change and fears of being considered incompetent. Upon realising that they actually shared these frustrations and challenges, they started to listen and pay attention to each other. This made the participants aware of their own and the others' focus, work practices and competences, and that they shared the same basic concern: the patients. An authentic meeting was thereby established where it became legitimate, sufficient and credible for the nurses to participate as themselves. Letting down their initial guard enabled them to meet each other as individuals and group members where 'we are all experts in our own fields'. They continued the workshop in an atmosphere that recognised their different competences, skills, specialisations and powers, while also realising that one group of nurses/one hospital ward could not function without the others.

This insight into one another's work conditions revealed that the work practices were more specialised and complicated than the simplified version visualised in the checklist format of the design proposal. The participants were able to listen to one another to find common ground, not in spite of their differences, but rather by acknowledging and learning from their differences.

As lessons learned from our case, we observed certain 'enablers' that established genuine participation. Establishing awareness of the initial relational dynamics caused by latent tensions among the participants, for example, contributing to an 'us versus them' sentiment, was important for the nurses to establish an authentic meeting as a result of the participants letting down their guard. Noergaard et al. (2017) mention the challenge of engaging healthcare staff in a design project involving both patients and healthcare staff, however, they do not elaborate or reflect on this issue, and rather state the challenge as a lesson learned: it is difficult to engage healthcare staff in PD. In our case, the relations between the ICU and the general wards (the ICU being the 'strongest'), and between the nurse-researcher and the other nurses (the nurse-researcher being in charge of the project and its agenda and potentially allied with management), had to be reflected on for these dynamics to change into a 'collaborative us'. The project and the design approach created an opportunity and a space for voicing, explicating and debating the frustrations inherent in the relational dynamics, which was a prerequisite for the participants to engage genuinely. 
The lessons we learned emphasise the need for participatory design projects in which practitioners collaborate across specialties. The importance of meeting one another where you are, and who you are, putting a face on the people behind 'the others' and establishing awareness of your own opinions comes to the fore.

\subsection{Participating with themselves}

After letting down their guard, the nurses realised that they were 'in the same boat', and they started to work as a group with a common goal. In healthcare, nurses are used to standardised procedures, but to standardise the patients would contradict their strong belief in individualised patient care. The ICU follow-up included a procedure for collaboration between wards with different work routines and work conditions. The participants learned from one another's practices in order to investigate and discuss what would be a meaningful follow-up plan. Once the participants acknowledged one another for their differences in skill and competence, they chose to listen with a new openness to one another — they became present, attentive and engaged.

The learning was collaborative: nurses learning from other nurses, the nurse-researcher learning from nurses and the nurses learning from the nurse-researcher. Collaborative learning included participants learning both from an individual perspective and from a group perspective, reflecting on their own perspectives as well as considering those of others. It was essential for nurses to learn from one another because the ICU follow-up procedure addressed collaboration between different specialised wards. Mutual learning is a key topic within participatory design (e.g. Beguin, 2003; Bratteteig, 1997). It has been depicted as a bidirectional knowledge-building process where designers seek to gain an understanding of user-participants' situations, contexts, needs and desires, while user-participants require knowledge from the designers about the design process and different design options, technological conditions, possibilities and constraints (Bødker et al., 2004; Kensing $\&$ Munk-Madsen, 1993). Our conceptual framing of genuine participation elaborates on this perspective of learning with a focus on the conditions for collective learning to emerge in the quality of communication between participants.

The nurses were able to sense how they felt about the nurse-researcher's proposal for the collaborative tool supporting the ICU follow-up plan. At first, they discussed the proposal by maintaining the design proposal's checklist format. However, upon reflecting on how to use the checklist in their everyday work, they were able to see its limitations. They started to perceive the 
design proposal as something that was trying to control, rather than support, them through the use of checkmarks and time stamps. They sensed a general protest over what was at stake and what they perceived as undermining their professionalism. This opened the door to debating the checklist format's validity as a collaborative tool in the follow-up, and enabled them to object to and reject the design proposal.

As lessons learned from our case, we observed that the nurses participating 'as themselves' and the experience of 'being in the same boat' facilitated a mutual and collective learning process. The nurses' presence arising from participating 'with themselves' was a prerequisite for their ability to sense what was at stake in terms of the product's design flaw. Giving the nurses an opportunity to openly express their opinions affected the design process and had important implications for it.

These observations recognise the importance of learning and the ability to reflect on the issues at stake in order for participants to be able to meaningfully design for themselves. In a collaborative design project, the participants must establish their common ground in order for the design to be meaningful and useful for everyone.

\subsection{Participating for the task and the project}

By rejecting the nurse-researcher's design proposal, the nurses embraced the importance of their participation, and they realised that the project could not and would not succeed without them. They also began to appreciate that the project and its intended outcome was a truly custom-made solution intended to meet their needs and desires. By establishing openness and creating an arena in which possibilities could be explored, the nurses were able to contribute to the now shared and agreedupon goal: designing a collaborative tool for ICU follow-up. They started to discuss alternatives that would accommodate and support their profession and acknowledge the differences between the four wards. They established a shared design vision based on an attention list (a listing of tasks/issues that the nurses needed to pay attention to within the first 24 hours with regard to the patient: e.g. lounge physiotherapy 6 times a day, stagnation of secretions or similar, but not 'tick off' or 'do X' according to a pre-set schedule) that replaced the checklist, which made sense in their daily work lives by supporting their knowledge and skills rather than controlling them. They acknowledged their stake in the project, and their engagement and responsibility was articulated in their request for another workshop. 
Participating as themselves and with themselves framed the conditions for genuine participation in the project but also challenged the nurse-researcher because she had to set aside her expectations for how to conduct research, as well as alter her design proposal. Genuine participation ensured that different participants, as well as the nurse-researcher, boarded 'the same boat' in terms of sharing and agreeing upon the goals of the design project. The nurses taking ownership of the design increased the possibility of the design product's use being more sustainable, which the initial design proposal made by the nurse-researcher would not have been able to achieve. The result challenged the traditional checklist format that is well known by hospital staffs and commonly used in clinical guidelines. Instead, the nurses' design acknowledged their different expertise and work contexts without undermining one kind of expertise in favour of another: we are all experts within our own fields.

\subsection{Being in-between roles}

Reflecting on roles (user-participants, designers and researchers, among others) is increasingly entering the design field. Pihkala and Karasti (2016, p. 28) stress the importance of 'creating a variety of participations beyond pre-set roles', which aligns with our understanding of genuine participation. The role of the researcher or facilitator in PD processes often remains invisible and one's share in the participation is not considered (Karasti, 2010). Some authors have started to discuss the PD researcher's role (e.g. Karasti, 2001; Luck, 2003, 2007; Pihkala \& Karasti, 2016). For example, Luck (2003, p. 524) discusses earlier research in architecture that challenges the role of the architect when users participate in the designing as 'illegal architects'. In our study, the 'illegal participant' appeared to be the designer, whose initial design proposal was supposed to be the basis for the nurses' further design and development but whose work was actually rejected. An opening for genuine participation was facilitated by the dynamic, collective reflection and collaborative learning by the entire group of participants, regardless of the traditional pre-set role of either designer-researcher or user-participant.

The nurse-researcher played an important role by acknowledging and respecting the nurses' changes to the ICU follow-up plan and allowing them to take ownership of the project. She managed to emancipate herself from her initial stance of having to 'know it all' as a researcher and from the unspoken hierarchy of her position as the creator of the project and its vision. On the one hand, being in-between roles meant that the nurse-researcher experienced benefits and limitations as 
an insider; as a colleague, a confidant as well as an outsider — someone asking more of the already busy nurses - it strengthened her presence and improved her understanding of the professional arguments and reasoning behind the nurses taking responsibility for the design. On the other hand, being in-between roles created an opportunity for the participants to speak freely and focus on both positives and negatives in order to be understood and to be invited to influence procedures undertaken across wards and in their management.

The lessons learned from being in-between roles as a designer/facilitator in these local, situated design activities include humility when facing the participants' expert knowledge, appreciating the differences and the importance of being able to speak freely using professional language. Genuine participation challenged the initially assumed role of the nurse-researcher as being 'the person in charge'. Because she was in-between roles and a part of the community of practice, the nurseresearcher also went through transformations towards genuine participation as the entire group of participants reflected and learned collectively and in collaboration. The nurse-researcher was able to leave her predetermined role and join in as an equal participant, which made her more credible and authentic to the fellow participants.

\section{Conclusion}

Our analysis and findings are based on small-scale, situated accounts from a single case study. While it might be problematic to generalise from these situated observations, by providing our particular perspective on genuine participation in concrete, situated design practices, and by providing insights into a situation (through the nurse-researcher) that would be difficult for any other person to observe, our contribution is unique. Applying our conceptual framework to the analysis contributes to our understanding of transformations towards genuine participation, with regard to the user-participants as well as the nurse-researcher, and with regard to how these transformations occurred. The insights provide a novel perspective on how the participants engaged in reflecting and learning together, based on fundamental human dimensions of authentic and focused presence. The result of the design process led to the nurses making a specific and significant contribution to a redesign that challenged the standardised guidelines and ways of thinking in healthcare settings.

While there is continued interest in the existing notions of genuine participation, we elaborate on a newly proposed perspective rooted in psychotherapeutic research to address interpersonal 
dimensions of the contact quality between participants and the positions that the participants may choose to take when they meet. This perspective 'aims for the ideal of participants being able to participate as themselves, with themselves, and for the task and the project, that is, characterized by genuine focused presence' (Simonsen and Storm, 2016, p. 48). Our conceptual framing offers a new take on the concept of genuine participation that includes an interpersonal dimension. We propose our framing as an analytic lens illuminating the premise of the participants to act authentically, credibly, attentively, and with a focused presence, that is, the conditions enabling engagement in genuine participation. This entails expanding the traditional view of mutual learning as bidirectional (user vs. designer) towards collective reflection, where the conditions for collective learning within the entire group of participants can emerge. It also opens up a new area of study that will hopefully increase our understanding of — and ability to enable and facilitate — transformations towards genuine participation.

\section{Acknowledgements}

This Ph.D. project was co-funded by Roskilde University, Region Zealand, Nykøbing F. Hospital, the Health Foundation (Grant number 2014B001), the Edith \& Henrik Henriksen's Memorial Fund (Grant number 50892), and supported by a research grant from the Velux Visiting Professor Program of VILLUM FONDEN (Grant number 10770).

Special thanks are due to the ICU, the medical ward for pulmonary diseases (230), the surgical ward (320), and the orthopaedic ward (330) at Nykøbing F. Hospital, Region Zealand, Denmark; particular gratitude is extended to the eight nurses and the clinical specialist who genuinely participated in the design workshops.

\section{References}

Arnstein, S. (1969). The ladder of citizen participation. Journal of the Institute of American Planners. Journal of the Institute of American Planners, 4(34), 216-224. Retrieved from https://en.wikipedia.org/wiki/Participation_(decision_making)

Bannon, L. J., \& Ehn, P. (2013). Design: design matters in Participatory Design. In J. Simonsen \& T. Robertson (Eds.), Routledge International handbook of Participatory Design (pp. 37-63). New York, NY, USA: Routledge.

Beguin, P. (2003). Design as a mutual learning process between users and designers. Interacting with Computers, 15(5), 709-730.

Brandrup, M., \& Østergaard, K. (2015). Conducting workshops in a busy clinical environment. In E. M. Piras \& G. Ellingsen (Eds.), The 5th International workshop on Infrastructures for Health Care (IHC) June 18-19, 2015. Trento, Italy: USB. 
Bratteteig, T. (1997). Mutual learning. Enabling cooperation on systems design. In K. Braa \& E. Monteiro (Eds.), Proceedings of IRIS'20 (pp. 1-20).

Bratteteig, T., \& Wagner, I. (2014). Decision-Making in Design. In Disentangling Participation. Computer Supported Cooperative Work (pp. 13-22). Springer, Cham. https://doi.org/http://doi.org/10.1007/978-3-319-06163-4_2

Briefs, U., Ciborra, C., \& Schneider, I. (1983). Systems Design For, With, and By the Users. (U. Briefs, C. Ciborra, \& I. Schneider, Eds.). Amsterdam, Netherlands: North-Holland.

Bødker, K., Kensing, F., \& Simonsen, J. (2004). Participatory IT Design: Designing for Business and Workplace Realities. Cambridge, MA: MIT Press.

Cornwall, A. (2008). Unpacking "Participation": models, meanings and practices. Community Development Journal, 43(3), 269-283.

Crilly, N. (2015). Fixation and creativity in concept development: The attitudes and practices of expert designers. Design Studies, 38, 54-91. https://doi.org/http://dx.doi.org/10.1016/j.destud.2015.01.002

Greenbaum, J. (1991). Design at work, cooperative design of computer systems. In J. Greenbaum \& M. Kyng (Eds.), Design at Work: Cooperative design of computer systems. Hillsdale, N.J: Lawrence Erlbaum Asociates.

Hales, B. M., \& Pronovost, P. J. (2006). The checklist - a tool for error management and performance improvement. Journal of Critical Care, 21(3), 231-235. https://doi.org/http://dx.doi.org/10.1016/j.jcrc.2006.06.002

Hägerfors, A. (1994). Co-Learning in Participative Systems Design: Enhancements of Genuine Participation by Consideration of Communication and Group Dynamics [Doctoral Dissertation]. Lund University, Sweden.

Iivari, N., \& Kinnula, M. (2016). Inclusive or Inflexible: A Critical Analysis of the School Context in Supporting Children's Genuine Participation. In W. Barendregt \& M. Obaid (Eds.), Proceedings of the 9th Nordic Conference on Human-Computer Interaction (pp. 1-10). New York, NY, USA: ACM. https://doi.org/10.1145/2971485.2971531

Karasti, H. (2001). Increasing sensitivity towards everyday work practice in system design [Doctoral Dissertation]. University of Oulu, Finland.

Karasti, H. (2010). Taking PD to multiple contexts: A response to Kyng. Scandinavian Journal of Information Systems, 22(1), 85-92, Article 8, http://aisel.ais-net.org/sjis/vol22/iss1/8.

Kensing, F., \& Greenbaum, J. (2013). Heritage. Having a say. In J. Simonsen \& T. Robertson (Eds.), Routledge International handbook of Participatory Design (1st ed., pp. 21-36). New York: Routledge.

Kensing, F., \& Munk-Madsen, A. (1993). PD: Structure in the Toolbox. Commun. ACM, 36(6), 7885. https://doi.org/10.1145/153571.163278

Luck, R. (2003). Dialogue in participatory design. Design Studies, 24(6), 523-535. https://doi.org/http://dx.doi.org/10.1016/S0142-694X(03)00040-1

Luck, R. (2007). Learning to talk to users in participatory design situations. Design Studies, 28(3), 217-242. https://doi.org/http://dx.doi.org/10.1016/j.destud.2007.02.002

McDonnell, J. (2016). Scaffolding practices: A study of design practitioner engagement in design education. Design Studies, 45, Part A, 9-29. https://doi.org/http://dx.doi.org.molly.ruc.dk/10.1016/j.destud.2015.12.006

Noergaard, B., Sandvei, M., Rottmann, N., Johannessen, H., Wiil, U., Schmidt, T., \& Pedersen, S. S. (2017). Development of a Web-Based Health Care Intervention for Patients With Heart Disease: Lessons Learned From a Participatory Design Study. JMIR Research Protocols, 6(5), e75. https://doi.org/10.2196/resprot.7084

Pihkala, S., \& Karasti, H. (2016). Reflexive Engagement: Enacting Reflexivity in Design and for 
"Participation in Plural." In R. C. Smith, A. M. Kanstrup, \& C. Bossen (Eds.), Proceedings of the 14th Participatory Design Conference: Full Papers - Volume 1 (pp. 21-30). New York, NY, USA: ACM. https://doi.org/10.1145/2940299.2940302

Robertson, T., \& Simonsen, J. (2013). Participatory Design: An Introduction. In J. Simonsen \& T. Robertson (Eds.), Routledge International handbook of Participatory Design (pp. 1-18). New York, NY, USA: Routledge.

Robertson, T., \& Simonsen, J. (2013). Participatory Desing. An introduction. In J. Simonsen \& T. Robertson (Eds.) (1st ed., pp. 1-17). New York: Routledge.

Robertson, T., \& Wagner, I. (2013). Ethics: engagement, representation and politics-in-action. In J. Simonsen \& T. Robertson (Eds.), Routledge International handbook of Participatory Design2 (pp. 64-85). New York, NY, USA: Routledge.

Siemsen, I. M. D. (2011). Patientovergange [Patient transfers], Doctoral Dissertation [in Danish, including English summary]. DTU Management. DTU Management, Denmark. https://doi.org/978-87-92706-05-8

Simonsen, J., \& Storm Jensen, O. (2016). Contact Quality in Participation: A "Sensethic" Perspective. In R. C. Smith, A. M. Kanstrup, \& C. Bossen (Eds.), Proceedings of the 14th Participatory Design Conference: Short Papers, Interactive Exhibitions, Workshops - Volume 2 (pp. 45-48). New York, NY, USA: ACM. https://doi.org/10.1145/2948076.2948084

Simonsen, J., Svabo, C., Strandvad, S. M., Samson, K., Hertzum, M., \& Hansen, O. E. (Eds.). (2014). Situated Design Methods (1st ed.). Cambridge, Massachusetts, London, England: The MIT Press.

Simonsen Jesper \& Robertson, T. (Ed.). (2013). Routledge International Handbook of Participatory Design. 711 3rd Ave, New York, NY 10017: Routledge.

Smith, R. C., Bossen, C., \& Kanstrup, A. M. (2017). Participatory design in an era of participation. CoDesign, 13(2), 65-69. https://doi.org/10.1080/15710882.2017.1310466

Storm Jensen, O. (1998). Psykoterapeutens autenticitet - terapiens afgørende led. Om at tage "at tage klienten alvorligt" alvorligt nok [The Authenticity of the Psychotherapist - the Critical Element of Psychotherapy. - On taking "taking the client seriously" seriously enough (In. Psyke \& Logos, (19), 271-286.

Storm Jensen, O. (2002). Krop, selv og virkelighed - Skal vi snakke om selvet eller være os selv? [Body, self and reality - should we talk about the self or be ourselves?]. In P. Bertelsen, M. Hermansen, \& J. Tønnesvang (Eds.), Vinkler på selvet - En antologi om selvbegrebets anvendelse i psykologien. (pp. 119-146). Aarhus, Denmark: Klim.

van Sluisveld, N., Zegers, M., Westert, G., van der Hoeven, J. G., \& Wollersheim, H. (2013). - A strategy to enhance the safety and efficiency of handovers of ICU patients: study protocol of the pICUp study. - Implementation Science : IS, 8(1), 67. https://doi.org/- 10.1186/1748-59088-67 